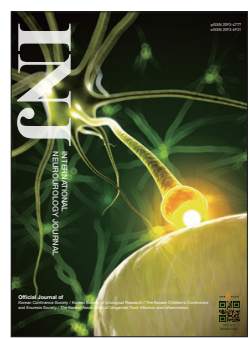

\title{
Mitochondrial Dysfunction as a Cause of Neurological Diseases
}

\author{
Chang-Ju Kim (iD https://orcid.org/0000-0003-4749-5795 \\ Guest Editor \\ Department of Physiology, College of Medicine, Kyung Hee University, Seoul, Korea \\ E-mail: changju@khu.ac.kr
}

In the present issue of the International Neurourology Journal (INJ), we focused on the mitochondria as a fundamental pathogenesis of incurable neurological diseases. Many recent studies have tried to find out the causes of diseases in the dysfunction of cell organelles.

Synapse loss is an early progressive pathologic symptom of Alzheimer disease (AD), which causes cognitive decline and memory loss. Tang et al. [1] reviewed how synaptic mitochondria lesions contribute to the pathogenesis of $\mathrm{AD}$ and how antioxidant therapies target mitochondria in $\mathrm{AD}$. Cho et al. [2] investigated the role of growth arrest and DNA-damage-inducible protein 45 beta (Gadd45b) on global ischemia. They showed the association of Gadd45b with neuronal cell death and mitochondrial dysfunction [2]. Yoo et al [3] investigated the effects of single-bout exercise on mitochondrial function, dynamics (fusion, fission), and mitophay in cardiac and skeletal muscle. They found that a single-bout exercise improves mitochondrial function without affecting mitochondrial dynamics and mitophay [3]. Anticancer drug, doxorubicin (DOX), causes damage to mitochondrial DNA, and then results in muscle weakness and fatigue. Park et al. [4] evaluated the protective effect of treadmill running on DOX-induced muscle damage. In their study, treadmill exercise suppressed DOX-induced apoptosis and prevented deterioration of mitochondria function in muscle [4]. Kim et al. [5] used BMAL1 knockdown transgenic mice and examined the effects of treadmill exercise on memory impairment due to the circadian rhythm disruption. In their study, treadmill exercise improved memory function through enhancing the expressions of glucocorticoid receptor and the fac- tors related to neurogenesis and memory consolidation. They concluded that exercise acts as the zeitgeber that resets the internal body clock, such as light or temperature [5].

Mitochondrial dysfunction is suggested as the underlying mechanism of many diseases, including brain diseases. In addition, changes in the circadian rhythm also interfere with learning and memory. For this issue, we recruited the recent studies related with mitochondria and circadian rhythm. Through this process, INJ will have the opportunity to combine recent knowledge with urologic disorders. I appreciate to the authors for contributing the valuable articles.

- Conflict of Interest: No potential conflict of interest relevant to this article was reported.

\section{REFERENCES}

1. Tang J, Oliveros A, Jang MH. Dysfunctional mitochondrial bioenergetics and synaptic degeneration in Alzheimer's disease. Int Neurourol J 2019;23(Suppl 1):5-10.

2. Cho CH, Byun H, Jover-Mengual T, Pontarelli F, Dejesus C, Cho AR, et al. Gadd45b acts as neuroprotective effector in global ischemia-induced neuronal death. Int Neurourol J 2019;23(Suppl 1):11-21.

3. Yoo SZ, No MH, Heo JW, Park DH, Kang JH, Kim JH, et al. Effects of acute exercise on mitochondrial function, dynamics, and mitophagy in rat cardiac and skeletal muscles Int Neurourol J 2019; 23(Suppl 1):22-31.

4. Park SS, Park HS, Jeong H, Kwak HB, No MH, Heo JW, et al. Treadmill exercise ameliorates chemotherapy-induced muscle 


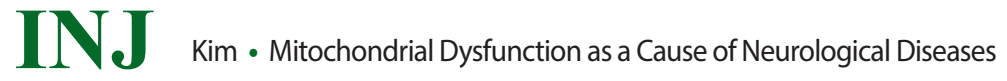

weakness and central fatigue by enhancing mitochondrial function and inhibiting apoptosis Int Neurourol J 2019;23(Suppl 1):32-9.

5. Kim SE, Ko IG, Ji ES, Jin JJ, Hwang L, Kim SH, et al. Treadmill exercise alleviates circadian rhythm disruption-induced memory deficits by activation of glucocorticoid receptor and brain-derived neurotrophic factor-dependent pathway. Int Neurourol J 2019; 23(Suppl 1):40-9. 